\title{
Análise de aproximações das concepções presentes em questões associadas ao ensino de química aplicadas no novo Enem com as concepções do enfoque CTS
}

\author{
Analysis of the approximations of the conceptions present in issues \\ associated to the teaching of chemistry applied in the new Enem with \\ the conceptions of the STS approach
}

Jorge Raimundo da Trindade Souza ${ }^{1}$

Licurgo Peixoto de Brito²

\section{Resumo}

O Exame Nacional do Ensino Médio (Enem) compreende a avaliação de habilidades e competências essenciais para a formação cidadã, um dos pressupostos da perspectiva educacional Ciência, Tecnologia e Sociedade (CTS). Esta investigação qualitativa, com aspectos quantitativos, teve o objetivo de analisar concepções CTS nas questões associadas ao ensino de Química deste exame, no período compreendido entre 2009 a 2015 (novo Enem). Assim, neste estudo, foi preciso analisar o conteúdo e a estrutura das questões que possuem relação com o ensino de Química, examinando se e como ocorreu a aproximação destas questões com os princípios da perspectiva educacional CTS, e que condições determinam a mediação desta relação de proximidade. Como instrumento de análise das questões, foi utilizada a Análise Textual Discursiva (ATD). Entre as 156 questões analisadas, que são pertinentes ao ensino de Química, 46,1\% não apresentaram aproximação com os princípios do enfoque CTS; $32,1 \%$ mostraram aparente relação com estes pressupostos e 21,8\% estão associadas aos princípios do enfoque CTS. Os resultados mostraram que as questões do novo Enem apresentam aproximação, em diferentes níveis, dos princípios teóricos do enfoque CTS.

Palavras-Chave: Enfoque CTS; Ensino de Química; Enem.

\section{Abstract}

The National High School Examination (Enem) comprehends the evaluation of skills and competences fundamental to the exercise of citizenship, one of the objectives of the Science, Technology and Society (STS) approach. This qualitative research, which also adopts quantitative standards, has the objective of analyzing STS concepts in the issues associated to the chemistry teaching of this exam, in the period between 2009 to 2015 (new Enem), and the factors that influence these relations. For this, it was necessary to analyze the content and the structure of the questions associated to the teaching of Chemistry, examining if and

\footnotetext{
${ }^{1}$ Universidade Federal do Pará |jirts@ufpa.br

2 Universidade Federal do Pará | licurgo@ufpa.b
} 
how occurred the approximation of these questions with the principles of the STS educational perspective, and what conditions determine the mediation of this relation of proximity. As an instrument for analyzing the questions, the Discursive Textual Analysis (ATD) was used. Among the 156 analyzed questions, which are pertinent to the teaching of Chemistry, 46.1\% did not present an approximation with the principles of the STS approach; $32.1 \%$ showed an apparent relationship with these assumptions and $21.8 \%$ were associated with the principles of the STS approach. The results showed that the questions of the new Enem presented proximity, at different levels, to the theoretical principles of the STS approach.

Keywords: STS approach; Chemistry teaching; Enem

\section{Introdução}

O aumento de problemas ambientais, além das discussões sobre o papel da ciência e da tecnologia, exige uma educação científica e tecnológica dos cidadãos de maneira crítica e participativa, além de uma compreensão subjetiva. Exige, ainda, a construção de conhecimentos, habilidades e valores que, vinculados a interesses coletivos, possibilitem questionar, atuar e participar de soluções de problemas causados pelo desenvolvimento científico e tecnológico.

Pesquisadores da área da educação oferecem propostas para a inclusão dos estudantes em um processo educacional que thes proporcione fundamentação para posicionamentos críticos com valores éticos diante da sociedade que os cerca. Estes mesmos pesquisadores afirmam que as questões de caráter sociocientífico enfocam habilidades, competências e valores indispensáveis para tomar decisões com responsabilidade, em relação às questões de ciência e tecnologia na sociedade. Com esse fim, diversas propostas curriculares incorporam uma abordagem de Ciência Tecnologia e Sociedade (CTS), em uma perspectiva de reflexão sobre as consequências do desenvolvimento científico e tecnológico na sociedade. Para Santos,

[...] inserir a abordagem de temas CTS no ensino de ciências com uma perspectiva crítica significa ampliar o olhar sobre o papel da ciência e da tecnologia na sociedade e discutir em sala de aula questões econômicas, políticas, sociais, culturais, éticas e ambientais. Essas discussões envolvem valores e atitudes, mas precisam estar associadas à compreensão conceitual dos temas relativos a esses aspectos sociocientíficos, pois a tomada de decisão implica a compreensão de conceitos científicos relativos à temática em discussão. (SANTOS, 2007, p. 10).

Tratando do ensino da Química, no sentido do enfoque CTS, segundo Santos e Schnetzler (2010, p. 101),

[...] o objetivo central do ensino de Química para formar o cidadão é preparar o indivíduo para que ele compreenda e faça uso das informações químicas necessárias para a sua participação na sociedade tecnológica em que vive. Neste sentido, o ensino levaria o aluno a compreender os fenômenos químicos mais diretamente ligados à sua vida cotidiana, a saber manipular as substâncias com as devidas precauções, a interpretar as informações químicas transmitidas pelos meios de comunicação, a compreender e avaliar as aplicações e implicações 
tecnológicas, a tomar decisões diante dos problemas sociais relativos à Química.

De acordo com Santos e Schnetzler (2010), a frequência constante de fenômenos químicos no cotidiano da sociedade evidencia e legitima a imprescindibilidade dos membros desta sociedade estarem cientificamente esclarecidos em relação à importância da Química. No entanto, os conhecimentos escolares aprendidos nesta disciplina não são adequados no sentido de levar ao pleno desenvolvimento da cidadania. Para os autores ( $p$. 15) "o tratamento do conhecimento químico tem enfatizado que a Química da escola não tem nada a ver com a química da vida e os objetivos, conteúdos e estratégias do ensino de Química atual estão dissociados das necessidades requeridas para um curso voltado para a formação da cidadania".

O aluno poderia, por exemplo, interpretar instruções de embalagens sobre a utilização e conservação de produtos químicos, compreender cálculos inerentes à concentração dos ingredientes, relacionando-os com o preço e avaliar a sua toxidez (SANTOS; SCHNETZLER, 2010, p. 106). Estes mesmos autores (p. 102) informam que o ensino de Química para o cidadão deve estar centrado na interação de dois elementos fundamentais: a informação química e o contexto social, uma vez que o cidadão precisa compreender os fenômenos e os conceitos da ciência Química e perceber a sociedade em que vive.

Um evento que pode oportunizar a orientação do ensino de Química, no sentido de contribuir para uma sociedade mais justa, é o Enem, pois várias competências e habilidades (C\&H) presentes na matriz de referência de Ciências da Natureza e suas Tecnologias (CNT) do Enem apresentam aproximações aos princípios do enfoque CTS e/ou estão ligadas ao ensino de Química. Assim, nesta perspectiva, de acordo com Souza e Brito (2018, p. 722), o Enem pode mudar a concepção que a sociedade tem sobre os objetivos desta ciência e o conceito de que é uma disciplina abstrata, enciclopédica e com excessiva memorização de fórmulas, equações, símbolos, ou seja, de uma série de representações que, muitas vezes, são difíceis de serem compreendidas e que não apresentam significado. Para Mascio (2010, p.75), "o Enem não pretende e nem anuncia trabalhar a relação CTS, mas observa-se que existe uma aproximação e a educação CTS pode contribuir para uma melhor contextualização e consequentemente, uma avaliação mais ampla".

Para esta investigação, é enunciada a seguinte hipótese: "Existem aproximações, em diferentes níveis, entre os pressupostos teóricos do enfoque CTS com as questões associadas ao ensino de Química aplicadas neste exame.

Em face deste relato, o objetivo do presente estudo é o de analisar o conteúdo e a estrutura das questões do Enem associadas ao ensino de Química, no período de 2009 a 2015 (novo Enem) e investigar se estão presentes os pressupostos teóricos do enfoque CTS nas questões associadas ao ensino de Química aplicadas no novo Enem.

\section{Fundamentação das relações CTS}

Segundo Pinheiro, Silveira e Bazzo (2009, p. 2): Ciência, Tecnologia e Sociedade - CTS corresponde ao estudo das inter-relações existentes entre a ciência, a tecnologia e a sociedade, constituindo um campo de trabalho que se volta tanto para a investigação acadêmica como para as políticas públicas. 
Um conjunto de eventos que aconteceram a partir da metade do século $X X$, provocados pelo desenvolvimento científico e tecnológico, motivaram conflitos e inquietações na sociedade e geraram preocupações com o meio ambiente. Fernandes e Marques (2009, p. 2) citam que o movimento CTS surgiu em torno da década de 1960, na Europa e América do Norte, com diversos aspectos, anunciando a necessidade de discutir visões clássicas de CT que as compreendem como fontes incondicionais de bem-estar social.

Auler (2003, p. 3) relata que, devido à degradação ambiental e à associação da Segunda Guerra Mundial ao desenvolvimento científico e tecnológico, este progresso se tornou alvo de um olhar crítico, passando a ser objeto de debate político e com questionamento de movimentos sociais sobre as consequências negativas da CT sobre a sociedade. O autor destaca a importância creditada à obra A Estrutura das Revoluções Científicas (1962), do físico-historiador Thomas Kuhn que, ao questionar a concepção tradicional de ciência, em âmbito acadêmico, gerou "novas reflexões no campo da História e Filosofia da Ciência".

De acordo com Auler (2007, p. 8) o movimento CTS tenciona, entre outros objetivos, provocar a tomada de decisões em relação à CT em outro nível. "Reivindicam-se decisões mais democráticas (mais atores sociais participando) e menos tecnocráticas". Para o autor, esse novo entendimento pode levar a quebra do contrato social para a CT, ou seja, o modelo linear de progresso. Neste modelo, "o desenvolvimento científico (DC) gera desenvolvimento tecnológico (DT), este gerando o desenvolvimento econômico (DE) que determina, por sua vez, o desenvolvimento social (DS - bem-estar social)". Para Bazzo et al. (2003), o desenvolvimento tecnológico não é um processo linear de acumulação de melhorias e sim, um processo multidirecional e quase-evolutivo de variação e seleção.

Todos esses pensamentos convergem para a necessidade de romper com a concepção clássica da relação de ciência e tecnologia com a sociedade, ou seja, o modelo linear de desenvolvimento, citado por López Cerezo (1998, p. 42), em que + ciência = + tecnologia = + riqueza $=+$ bem-estar social.

Particularmente no Brasil, essa é uma equação de difícil resolução, consequência das riquezas naturais abundantes, da desigualdade social entre regiões, da distribuição de renda e riqueza de modo desigual, da pequena oferta de empregos, da incipiente reorganização da estrutura fundiária, da tênue redistribuição das propriedades rurais mas, principalmente, da baixa formação escolar e da quase ausência de uma educação escolar científica e tecnológica com reflexos sociais.

Este quadro é propício para a predominância de um sistema capitalista que vise exclusivamente ao lucro e ao desenvolvimento a qualquer custo, com exploração acelerada de bens naturais, contando, neste caso, com o apoio da sociedade que neste contexto enxerga apenas a manutenção de empregos e a conveniente comodidade individual em detrimento do bem-estar coletivo e da preservação do meio ambiente.

Embora o estágio inicial do movimento CTS não tenha ocorrido na área educacional, a sala de aula se apresenta como um espaço propício para estabelecer reflexões que permitam as transformações apontadas por este movimento. Assim, na perspectiva de um ensino que conduza a uma educação científica baseada na ação e na construção social, com a participação pública em tomada de decisões relacionadas com ciência e tecnologia, ganhou força na área educacional, no início da década de 1980, o enfoque Ciência, Tecnologia e Sociedade (CTS). 
Souza et. al. (2016, p. 97) relatam que o "ensino de Ciências com um enfoque CTS institui, como principal objetivo, estabelecer relações entre os conhecimentos escolares com o desenvolvimento científico e tecnológico e sua aplicação na sociedade, resultando na formação de cidadãos alfabetizados cientificamente". Neste sentido, para que o ensino apresente caráter educativo, objetivando a educação cidadã, a escola deve ofertar condições e oportunidades para que o estudante estabeleça sua conduta nesta direção. Assim, espera-se que o aluno incentivado para o alcance de competências, futuramente possa desempenhar uma função ativa e responsável na sociedade.

As transformações sociais e econômicas observadas nas últimas décadas, no Brasil, exigem, portanto, do ensino de Ciências, uma nova postura, um novo objetivo. Na Figura 1, observa-se uma proposta de Brito e Gomes (2007, p.6) da trajetória que o ensino de Ciências deve percorrer desde a educação tradicional até a Tendência Atual (TA). O sentido da seta representa o caminho em direção a essa tendência.

Figura 1 - Representação da proposta de Brito e Gomes (2007) que mostra a trajetória do ensino tradicional até a abordagem CTS
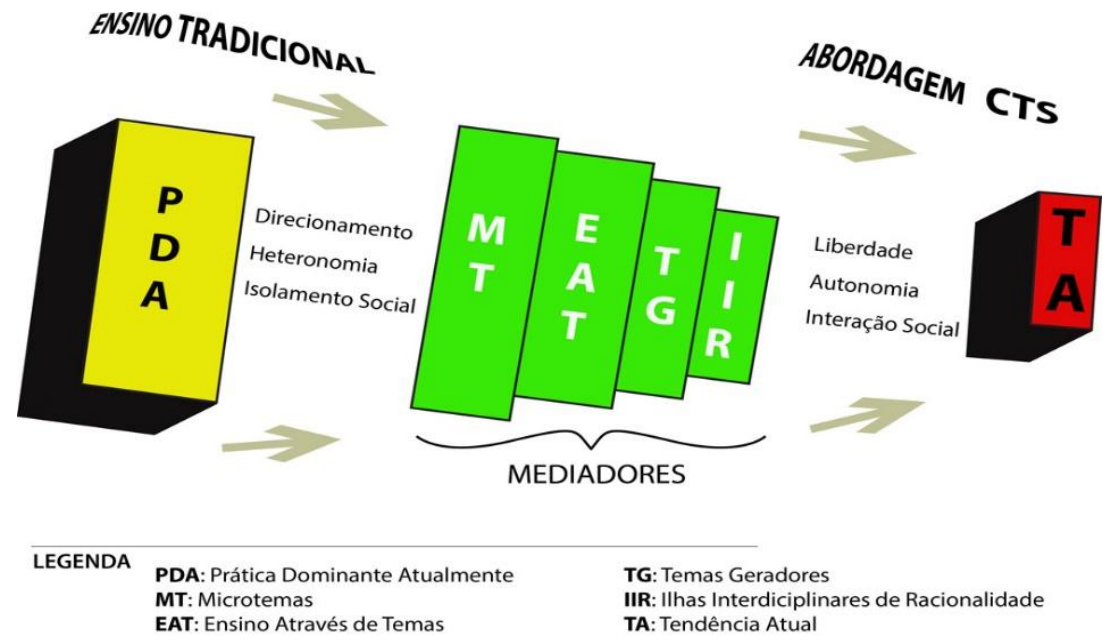

Fonte: Adaptado de Brito e Gomes (2007, p. 6).

A passagem da Prática Dominante Atualmente (PDA) para a TA não vai acontecer como se fosse um salto quântico, uma vez que a formação escolar tradicional está internalizada em um sistema educacional refratário às transformações pretendidas para um ensino de Ciências que atenda às exigências reais da sociedade contemporânea. Portanto, para romper com este modelo, as mudanças devem ocorrer gradativamente, com a implementação de algumas práticas intermediárias, como a utilização de Microtemas, Ensino Através de Temas, Temas Geradores e as Ilhas Interdisciplinares de Racionalidade. Assim, uma mudança paulatina, gradual e com uma certa progressão destas práticas, conduzida pelo professor e aplicada ao ensino de Ciências, delineia, ainda que de forma tênue, a perspectiva CTS.

No ensino de Química, por exemplo, os alunos poderiam ser estimulados a decidir criticamente pela utilização ou não de produtos de uso diário, após a construção de conhecimentos que apresentassem os benefícios e os malefícios que o consumo pode provocar para a saúde, levando em conta as consequências (benéficas e maléficas) para o meio ambiente e para a sociedade, as vantagens e desvantagens econômicas, incluindo as questões éticas associadas ao uso, à produção e à comercialização. 
Santos e Mortimer (2002, p. 115) comentam que a decisão de consumir um produto é adotada em função de sua aparência e qualidade, e raramente são considerados os aspectos sociais, ambientais e éticos implicados na sua produção. "Considerações de tal ordem poderiam, por exemplo, resultar na diminuição, a longo prazo, do consumo de embalagens descartáveis e de produtos que agridem a camada de ozônio". Isto pode, forçosamente, levar a uma reavaliação dos processos de fabricação.

Algumas pesquisas consultadas para este estudo apontam que a resistência de professores de Química se apresenta como um dos entraves para a adoção de práticas educacionais mais apropriadas em sala de aula (SANTOS, 2009 et al.; AULER; BAZZO, 2001; REIS; GALVÃO, 2008; SILVA; OLIVEIRA, 2009; PRUDÊNCIO, 2014). Sobre a implementação do enfoque CTS, um dos obstáculos citados nas pesquisas refere-se às concepções dos docentes sobre ciência e suas relações com a tecnologia e a sociedade. Essa reflexão nos leva a admitir que, apesar do potencial que a utilização dos conhecimentos químicos tem para proporcionar o bem-estar da sociedade, os interesses de uma organização social que visem apenas a lucros monetários, valorizando mais objetos do que pessoas, sobrepõem-se aos interesses sociais e humanísticos, que seriam próprios de uma educação CTS.

Nas orientações curriculares (BRASIL, 2006, p. 109) é anunciado que, no Ensino Médio, espera-se que "a Química seja valorizada, na qualidade de instrumento cultural essencial na educação humana, como meio coparticipante da interpretação do mundo e da ação responsável na realidade". De acordo com o que foi estabelecido nos Parâmetros Curriculares Nacionais $(\mathrm{PCN}+)$,

a Química pode ser um instrumento da formação humana que amplia os horizontes culturais e a autonomia no exercício da cidadania, se o conhecimento químico for promovido como um dos meios de interpretar o mundo e intervir na realidade, se for apresentado como ciência, com seus conceitos, métodos e linguagens próprios, e como construção histórica, relacionada ao desenvolvimento tecnológico e aos muitos aspectos da vida em sociedade. (BRASIL, 2002, p.87).

O Art. 26 das Diretrizes Curriculares Nacionais da Educação Básica (DCN) estabelece que o Ensino Médio deve ser norteado por objetivos e fundamentos que levem o aluno a consolidar e aprofundar os conhecimentos adquiridos no Ensino Fundamental; receber a preparação básica para a cidadania e o trabalho; se desenvolver como pessoa humana, incluindo a formação ética e estética, o desenvolvimento da autonomia intelectual e do pensamento crítico; e compreender os fundamentos científicos e tecnológicos presentes na sociedade contemporânea, relacionando a teoria com a prática (BRASIL, 2013, p. 71).

Em relação a esses contextos, Santos e Schnetzler (2010, p. 107), inferem que com os temas sociais da Química "pode-se ensinar os conceitos químicos necessários para o cidadão ser capaz de julgar, compreendendo a responsabilidade social que tem como tal".

De acordo com a Base Nacional Comum Curricular (BNCC) na etapa final do Ensino Fundamental os estudantes devem estar aptos para estabelecer vínculos ainda mais fortes entre

a ciência, a natureza, a tecnologia e a sociedade, o que significa lançar mão do conhecimento científico e tecnológico para compreender os fenômenos e conhecer o mundo, o ambiente, a dinâmica da natureza. Além disso, é fundamental que tenham condições de ser protagonistas na 
escolha de posicionamentos que valorizem as experiências pessoais e coletivas (BRASIL, 2018, p. 548).

No Ensino Médio, na determinação das competências específicas e habilidades da área de Ciências Natureza e suas Tecnologias foram assegurados conhecimentos conceituais tendo em vista o prosseguimento à proposta do Ensino Fundamental, sua importância no ensino de Física, Química e Biologia e sua apropriação ao Ensino Médio. Assim, na BNCC, é perceptível a proposta de "discutir o papel do conhecimento científico e tecnológico na organização social, nas questões ambientais, na saúde humana e na formação cultural, ou seja, analisar as relações entre ciência, tecnologia, sociedade e ambiente" (BRASIL, 2018, p. 549).

\section{Metodologia}

Segundo Gil (2010), um estudo caracteriza-se pelos critérios fins e meios. Quanto aos fins, esta pesquisa pode ser classificada como qualitativa, que adota também padrões quantitativos, exploratória, descritiva, teórica aplicada e se apoia em dados empíricos. Quanto aos meios, é uma pesquisa de campo, documental e bibliográfica.

A obtenção das informações solicitou a utilização de, pelo menos, duas técnicas de coleta de dados: observação e documentação. Para Ludke e André (1986, p. 26), a observação, que ocupa um lugar privilegiado na pesquisa educacional, permite um contato pessoal com a aproximação entre o pesquisador e o fenômeno investigado, sendo a vivência direta o mais indicado teste de verificação da ocorrência de um fato,

A Análise Textual Discursiva (ATD), método apropriado para a análise de dados e informações de natureza qualitativa (MORAES; GALIAZZI, 2007, p.7), foi empregada no sentido de analisar os itens de Química, assumidos aqui como dados a serem categorizados e analisados. Na ATD, o pesquisador parte da análise do material empírico para a abstração teórica, com interpretação e construção de argumentos, a partir de estabelecimento de categorias não excludentes entre si.

Com base no reconhecimento das questões associadas ao ensino de Química aplicadas no Enem, no período de 2009 a 2015, que apresentaram aproximação com o enfoque CTS, realizamos a categorização e a análise. Na medida em que os resultados foram surgindo, realizamos um processo de explicitação de relações entre eles no sentido da construção da estrutura de um metatexto, como orienta Moraes (2003, p. 201).

\section{Resultados e discussão}

Neste estudo, para se referir às questões aplicadas no novo Enem que envolvam noções de Química, utilizamos os termos "questões de Química" ou "questões associadas ao ensino de Química", pois pode ocorrer que questões elaboradas intencionalmente para aferir conhecimentos de Física ou Biologia exijam conhecimentos característicos do ensino de Química. As questões estão identificadas pela numeração progressiva correspondente na prova de cor azul. 
Análise de aproximações entre a concepção do enfoque CTS e as concepções presentes em questões associadas ao ensino de Química, aplicadas no Enem de 2009 a 2015

Neste estudo, foi utilizada a identificação de questões associadas ao ensino de Química realizada por Souza e Brito (2018), onde os autores, após a leitura das questões de CNT das edições do Enem de 2009 a 2015 (405 itens), identificaram grupos de questões que possuem diferentes níveis de aproximações com o ensino de Química. Nesses sete anos houve nove aplicações do Enem, já que ocorreram duas aplicações nas edições de 2010 e 2015.

No processo de seleção dos itens associados ao ensino de Química, algumas variáveis tiveram de ser analisadas, tais como C\&H envolvidas, conteúdos sugeridos pelos Enem para o ensino de Química, conteúdos sugeridos para as outras disciplinas da área de CNT, procedimento de resolução, comentário do Relatório Pedagógico-Enem e o nível educacional.

Para inferir que itens de CNT, aplicados no novo Enem, pertencem ao grupo de questões associadas ao ensino de Química, Souza e Brito (2018) realizam incialmente a distribuição destas questões em três categorias: 1) questões associadas diretamente ao ensino de Química; 2) questões que não estão fortemente ligadas ao ensino de Química, mas que exigem algum tipo de conhecimento desta disciplina; e 3) questões que não possuem nenhuma relação com o ensino de Química. Em seguida, a partir do exame do conteúdo das questões, ocorreu a junção dos itens das duas primeiras categorias que foram posteriormente analisadas em relação ao enfoque CTS. A Tabela 1 exibe o número das questões aplicadas no novo Enem que apresentam associação com o ensino de Química, utilizando como referência a prova de cor azul.

Tabela 1 - Número das questões (itens) associadas ao ensino de Química aplicadas no novo Enem

\begin{tabular}{|c|c|c|}
\hline ANO DE APLICAÇÃO & NÚMERO DO ITEM & TOTAL DE ITENS \\
\hline 2009 & $1,2,6,10,12,15,23,26,29,32,34,36,40,43,44$ & 15 \\
\hline $20101^{a}$ aplicação & $\begin{array}{c}50,53,55,57,58,59,60,63,65,67,69,72,73 \\
74,77,79,80,82,83,85,90\end{array}$ & 21 \\
\hline $20102^{\mathrm{a}}$ aplicação & $\begin{array}{c}53,55,56,60,62,73,74,75,76,77,79,80,83 \\
87,90\end{array}$ & 15 \\
\hline 2011 & $\begin{array}{c}50,51,52,54,55,58,59,62,71,72,75,79,80,81 \\
83,85,90\end{array}$ & 17 \\
\hline 2012 & $\begin{array}{c}46,49,53,58,59,63,66,69,70,71,76,79,82 \\
84,86,89,90\end{array}$ & 17 \\
\hline 2013 & $\begin{array}{c}46,47,49,51,54,58,59,64,67,68,69,71,74,77, \\
81,86,90\end{array}$ & 17 \\
\hline 2014 & $\begin{array}{c}47,48,49,51,52,54,56,58,59,63,65,66,70,71, \\
75,77,78,80,83,86,88\end{array}$ & 21 \\
\hline $20151^{a}$ aplicação & $\begin{array}{c}47,51,52,55,58,59,60,62,71,73,76,77,80,81 \\
84,90\end{array}$ & 16 \\
\hline $20152^{\mathrm{a}}$ aplicação & $\begin{array}{c}50,51,52,53,56,59,61,68,69,70,71,73,74,76, \\
80,82,84\end{array}$ & 17 \\
\hline \multicolumn{2}{|r|}{ TOTAL } & 156 \\
\hline
\end{tabular}

Fonte: Souza e Brito (2018). 
Para a categorização das questões do novo Enem que possuem associações com o ensino de Química e com o enfoque CTS utilizamos, como principal referência para o estabelecimento das categorias, os pressupostos do enfoque CTS consignados em Santos e Schnetzler (2010), que sugerem os objetivos fundamentais, quando se deseja incluir o enfoque CTS nos processos de ensino e de aprendizagem.

Nesta investigação, estabelecemos três categorias de análise, em função do nível de aproximação entre as questões do Enem associadas ao ensino de Química com os pressupostos do enfoque CTS. As categorias, e os respectivos descritores construídos para o seu detalhamento, foram formadas buscando abarcar todos os itens analisados em grupos de afinidades claramente definidos, sendo organizadas e denominadas do seguinte modo:

\section{Questões associadas aos pressupostos do enfoque educacional CTS}

- Questões que oferecem dados científicos e tecnológicos em uma situação-problema, exigindo conhecimentos associados a questões sociais e que, geralmente, pedem interpretações qualitativas.

- Questões que solicitam análise de processos naturais e tecnológicos, com interpretações sociais associadas ao mundo real do estudante, compreendendo a interdisciplinaridade, integrando-a com aspectos sociais, éticos ou econômicos.

- Questões que utilizam temas químicos sociocientíficos, oportunizando, como sugere Santos e Schnetzler (2010, p. 112), a contextualização do conteúdo químico com o cotidiano do aluno. Tais questões permitem verificar habilidades referentes à cidadania, como a capacidade de tomada de decisão, propiciando discussões de aspectos sociais que solicitam dos estudantes posicionamento crítico, ou seja, itens com uma abordagem baseada na integração entre os conceitos químicos e os aspectos sociais.

Questões superficiais e aparentemente associadas aos pressupostos do enfoque educacional CTS

- Questões com leve aproximação dos pressupostos da perspectiva educacional CTS que apenas tangenciam temas importantes. Itens que possibilitam reflexões baseadas em evidência científica sobre problemas relacionados à aplicação da ciência e da tecnologia na sociedade; no entanto, sem uma apreciação do modo de agir na sociedade e sobre o meio ambiente.

- Questões que fazem alguma referência ao cotidiano dos alunos, porém em um contexto que não exigem dos estudantes competências e habilidades associadas ao enfoque CTS como, por exemplo, interpretações e intervenções sociais e o estabelecimento de relações qualitativas.

- Questões que não solicitam argumentação nem elaboração de proposta, apenas a indicação da resposta e não requerem domínio de responsabilidade social envolvida em decisão de natureza CTS.

Questões que não permitiram a construção de associações ou de aproximações com os pressupostos do enfoque CTS

- Questões que não apresentam potencial de interpretação CTS e, portanto, não se enquadram nas duas categorias já apresentadas. 
- Questões com baixo valor cognitivo, sem uma visão de uma situação-problema, meramente conteudistas, em que apenas é exigido do aluno a memorização de fórmulas, conceitos, nomes científicos, acontecimentos, entre outros, em detrimento da reflexão crítica.

- Questões pretensamente contextualizadas, com rara coerência e coesão entre suas partes (texto-base, enunciado e alternativas), e que exigem conhecimentos que provavelmente serão arquivados ou esquecidos, a não ser, talvez, em situações de ensino, muitas vezes abstratas ou inócuas.

No Quadro 1, podem-se observar as questões associadas ao ensino de Química correspondentes a cada categoria de análise estabelecida. A categoria 1 agrupa as questões associadas aos pressupostos do enfoque educacional CTS; a categoria 2 reúne as questões superficiais e aparentemente associadas aos pressupostos do enfoque educacional CTS; e na categoria 3 estão as questões que não permitiram a construção de associações ou de aproximações com os pressupostos do enfoque CTS.

Quadro 1 - Questões associadas ao ensino de Química distribuídas por categorias de análise em relação ao enfoque CTS

\begin{tabular}{|c|c|c|c|}
\hline & \multicolumn{3}{|c|}{ CATEGORIAS } \\
\hline & 1 (CTS) & 2 (CTS aparente) & 3 (sem CTS) \\
\hline 2009 & $1,10,23,34$ & $2,6,12,26,40$ & $15,29,32,36,43,44$ \\
\hline $20101^{a}$ & $\begin{array}{l}53,57,59,60,63,67, \\
69,90\end{array}$ & $58,72,85$ & $\begin{array}{l}50,55,65,73,74,77,79, \\
80,82,83\end{array}$ \\
\hline $20102^{a}$ & $55,56,74,75,90$ & $53,62,73,76,77,79$ & $60,80,83,87$ \\
\hline 2011 & $51,71,80 \quad, 85$ & $\begin{array}{l}50,58,59,62,75,79, \\
90\end{array}$ & $52,54,55,72,81,83$ \\
\hline 2012 & $53,59,70,71,84$ & 69,82 & $\begin{array}{l}46,49,58,63,66,76,79, \\
86,89,90\end{array}$ \\
\hline 2013 & 46,67 & $\begin{array}{l}49,51,54,58,59,64, \\
69,71,74,\end{array}$ & $47,68,77,81,86,90$ \\
\hline 2014 & $47,49,52,86$ & $\begin{array}{l}48,54,56,70,71,75, \\
78,83,88\end{array}$ & $\begin{array}{l}51,58,59,63,65,66,77, \\
80\end{array}$ \\
\hline $20151^{a}$ & 58 & $47,55,80$ & $\begin{array}{l}51,52,59,60,62,71,73, \\
76,77,81,84,90\end{array}$ \\
\hline $20152^{a}$ & 53 & $50,68,74,76,80,84$ & $\begin{array}{l}51,52,56,59,61,69,70, \\
71,73,82\end{array}$ \\
\hline SUBTOTAL & $34(21,8 \%)$ & $50(32,1 \%)$ & $72(46,1 \%)$ \\
\hline TOTAL & & 156 & \\
\hline
\end{tabular}

Fonte: Dados da pesquisa.

Observa-se, no Quadro 1, que a investigação sobre a distribuição das questões de acordo com as categorias estabelecidas e suas aproximações à perspectiva CTS revela que a maior recorrência foi de questões alocadas na categoria três (46,1\%), seguidas de questões da categoria dois (32,1\%). O grupo de itens de menor recorrência no novo Enem foi o de questões pertencentes à categoria um (21,8\%), justamente as questões associadas aos pressupostos do enfoque educacional CTS. 
Esses resultados vão ao encontro do que afirmam Costa-Beber e Maldaner (2015, p. 48-49), em um estudo envolvendo conhecimentos químicos no novo Enem, ao verificarem que, mesmo as fundamentações teóricas deste exame estando mais próximas da noção de letramento científico, valorizando a função social desse conhecimento, o resultado gerado da análise das questões se aproximou mais da noção de alfabetização científica.

Os resultados também se aproximam das considerações de Mascio (2010, p. 76), quando este afirma que a triagem dos itens exibe um procedimento de "composição da prova do Enem que não parece permitir abordar a Química de forma problematizadora, promotora de reflexões mais profundas acerca das relações entre ciência, tecnologia e sociedade".

Segundo Moraes e Galiazzi (2006, p. 118), o processo de categorização da ATD, que reúne unidades de significados semelhantes, pode gerar vários níveis de categoria de análise, a partir das categorias primitivas. Com base nessas orientações, Souza e Brito (2018) iniciaram um movimento no sentido de observar e classificar as questões selecionadas em relação à ênfase que atribuem às inter-relações CTS, alcançando, novamente, por meio do agrupamento por afinidade de sentidos, as subcategorias ou categorias finais. As questões da categoria primitiva três não entram nesta análise por não permitirem associações, em nenhum nível, com os pressupostos do enfoque CTS.

Para a definição das subcategorias, neste estudo, também foi utilizada a seleção realizada por Souza e Brito (2018), que utilizaram a classificação sobre CTS proposta por Aikenhead (SANTOS; SCHNETZLER, 2010, p. 71). Assim, com base nesta proposta, os autores agruparam as categorias com maiores semelhanças entre si e estabeleceram três subcategorias, que estão descritas no Quadro 2.

Quadro 2 - Subcategorias e descritores das questões associadas ao ensino de Química

\begin{tabular}{|c|c|c|}
\hline Subcategoria A & Subcategoria B & Subcategoria C \\
\hline $\begin{array}{l}\text { CTS incorporado } \\
\text { casualmente como } \\
\text { elemento motivador }\end{array}$ & $\begin{array}{c}\text { Questões de Química } \\
\text { incorporadas ao enfoque } \\
\text { CTS }\end{array}$ & $\begin{array}{c}\text { Alusão ao conteúdo de } \\
\text { Química no conteúdo de } \\
\text { CTS }\end{array}$ \\
\hline Descritor & Descritor & Descritor \\
\hline $\begin{array}{l}\text { Questões tradicionais de } \\
\text { ensino de Química } \\
\text { acrescidas de alusão aos } \\
\text { princípios do enfoque } \\
\text { CTS, sem a utilização de } \\
\text { temas sociocientíficos. }\end{array}$ & $\begin{array}{c}\text { Questões com ênfase no } \\
\text { conteúdo de Química e } \\
\text { que abordam os conteúdos } \\
\text { das inter-relações CTS } \\
\text { utilizando temas } \\
\text { sociocientíficos. }\end{array}$ & $\begin{array}{l}\text { Questões em que o } \\
\text { conteúdo CTS é o foco } \\
\text { principal. O conteúdo de } \\
\text { Química é mencionado } \\
\text { apenas para indicar uma } \\
\text { vinculação às ciências. }\end{array}$ \\
\hline Questões & Questões & Questões \\
\hline \multirow{9}{*}{$\begin{array}{c}\text { Todas as questões da } \\
\text { categoria } 2\end{array}$} & 1,34 & 10,23 \\
\hline & $53,60,63,67,69,90$ & 57,59 \\
\hline & $55,56,74,75,90$ & \\
\hline & & $51,71,80,85$ \\
\hline & $53,59,70$ & 71,84 \\
\hline & 46,67 & \\
\hline & $47,49,52,86$ & \\
\hline & & 58 \\
\hline & 53 & \\
\hline 50 & $23(67,6 \%)$ & $11(32,4 \%)$ \\
\hline
\end{tabular}

Fonte: Souza e Brito (2018). 
Das 34 questões da categoria um, 23 (67,6\%) foram classificadas na subcategoria B e 11 $(32,4 \%)$ na subcategoria C. Como já foi destacado no Quadro 2, todas as questões inicialmente classificadas na categoria dois foram agrupadas na subcategoria A.

Observa-se, portanto, que uma maioria significativa das questões da categoria 1, que são aquelas que estão associadas aos pressupostos do enfoque educacional CTS, pertencem à subcategoria B, ou seja, são questões com ênfase no conteúdo de Química e que abordam os conteúdos das inter-relações CTS, utilizando temas sociocientíficos.

Um número menor de questões da categoria 1 foi alocado na subcategoria C. São itens em que o conteúdo CTS é o foco principal e apenas fazem menção ao conteúdo de Química, que é citado somente para indicar uma vinculação às ciências.

\section{Identificação dos conteúdos de Química em questões aplicadas no novo Enem}

Como parte da análise das questões de Química associadas ao enfoque CTS, buscouse identificar quais conteúdos desta disciplina escolar estão inseridos nos itens selecionados para esta pesquisa. No Quadro 3, observa-se uma síntese do processo de análise realizada por Souza e Brito (2018).

Como observação, fica o registro de que alguns itens estão associados conjuntamente com mais de um objeto de conhecimento. Assim, neste estudo, foi apreciado o objeto de conhecimento com maior proximidade da habilidade solicitada.

Quadro 3 - Síntese dos conteúdos presentes nas questões analisadas das subcategorias

\begin{tabular}{|c|c|c|c|c|}
\hline $\begin{array}{c}\text { Objetos de } \\
\text { Conhecimento }\end{array}$ & $\begin{array}{c}N^{\circ} \text { de Questões } \\
\text { da subcategoria A }\end{array}$ & $\begin{array}{c}N^{\circ} \text { de Questões } \\
\text { da subcategoria B }\end{array}$ & $\begin{array}{c}N^{\circ} \text { de Questões } \\
\text { da subcategoria C }\end{array}$ & Total \\
\hline $\begin{array}{l}\text { 1- Transformações } \\
\text { químicas }\end{array}$ & 3 & & 1 & 4 \\
\hline $\begin{array}{l}\text { 2- Representação das } \\
\text { transformações químicas }\end{array}$ & 5 & 1 & & 6 \\
\hline $\begin{array}{l}\text { 3- Materiais, suas } \\
\text { propriedades e usos }\end{array}$ & 3 & 2 & & 5 \\
\hline 4- Água & 10 (20\%) & 1 & & 11 \\
\hline $\begin{array}{l}\text { 5- Transformações } \\
\text { químicas e energia }\end{array}$ & 4 & 2 & 1 & 7 \\
\hline $\begin{array}{l}\text { 6- Dinâmica das } \\
\text { transformações químicas }\end{array}$ & & 1 & & 1 \\
\hline $\begin{array}{l}\text { 7-Transformação química } \\
\text { e equilíbrio }\end{array}$ & 9 & 1 & & 10 \\
\hline $\begin{array}{l}\text { 8- Compostos de } \\
\text { carbono }\end{array}$ & 5 & 2 & & 7 \\
\hline $\begin{array}{l}\text { 9- Relações da química } \\
\text { com as tecnologias, a } \\
\text { sociedade e meio } \\
\text { ambiente }\end{array}$ & 9 (18 \%) & 12 (52 \%) & 7 (63,6 \%) & 28 \\
\hline $\begin{array}{l}\text { 10- Energias químicas no } \\
\text { cotidiano }\end{array}$ & 2 & 1 & 2 & 5 \\
\hline Total & 50 & 23 & 11 & 84 \\
\hline
\end{tabular}

Fonte: Souza e Brito (2018). 
Nos itens da subcategoria A, em que o CTS é incorporado casualmente como elemento motivador, a maior incidência foi a do objeto de conhecimento "Água" (20\%). Os itens desta subcategoria foram inicialmente classificados na categoria dois, em que estão alocadas as questões superficiais e aparentemente associadas aos pressupostos do enfoque educacional CTS. Prudêncio (2014, p. 93), sustenta que, neste sentido, o enfoque CTS não é compreendido como um campo de conhecimento estruturado, sendo entendido "como uma espécie de metodologia cuja função principal é a de deixar o ensino mais atraente".

Observa-se que, nesta conceituação, a disciplina Química recebe um tratamento simplista no que se refere às reflexões da sua importância para a sociedade. Merece destaque, também, o fato de que o objeto de conhecimento "Água", é exibido na matriz de referência dissociado das questões sociais, o que leva a um distanciamento dos princípios do enfoque CTS, se aproximando do conteúdo clássico de Química, como solubilidade, concentração das soluções e o estudo das funções inorgânicas, entre outros. Esta utilização inadequada dos objetos de conhecimento pouco ajuda na exploração de aspectos sociocientíficos (ASC), como afirma Santos (2002, p. 270): "esse parece ser outro fator limitante, o fato de que determinados conteúdos favorecem mais a introdução de ASC do que outros".

A utilização inapropriada dos conhecimentos científicos privilegia em excesso o estudo memorialístico, muitas vezes com pouca significação para os aprendizes. Quando estes conhecimentos são aplicados adequadamente podem ser empregados nos processos de ensino e de aprendizagem de temas sociais associados ao desenvolvimento da ciência e da tecnologia.

Nos itens da subcategoria B (questões de Química incorporadas ao enfoque CTS), o objeto de conhecimento de "relações da química com as tecnologias, a sociedade e meio ambiente", é o que apresenta maior ocorrência (52\%), sendo um indicativo de que existe maior possibilidade de associação com os princípios do enfoque CTS quando esta relação se manifesta explicitamente no título do objeto de conhecimento.

No entanto, objetos de conhecimento que não apresentam esta relação nos títulos também possuem amplo potencial no sentido de serem utilizados para reflexões acerca dos princípios do enfoque CTS e envolvam questões sociais importantes para a sociedade. Por exemplo, Firme (2012, p. 16), investigando como professores de química constroem seus discursos quando trabalham conceitos científicos da Termoquímica numa abordagem CTS, apresenta o potencial que ensino de Termoquímica possui para discussões de questões sociocientíficas que afetam a sociedade como, por exemplo, as "causas da poluição do ar provocada pela queima de combustíveis automotivos".

Nos itens da subcategoria C, com menção ao conteúdo de Química no conteúdo de CTS, do mesmo modo, prepondera o objeto de conhecimentos "relações da química com as tecnologias, a sociedade e meio ambiente" (63,6 \%). São questões que não têm o foco na abordagem de conteúdos científicos, evidenciando tão somente os aspectos da perspectiva educacional CTS, o que, também, não é o mais adequado para o desenvolvimento da formação cidadã. No entanto, esta subcategoria foi a que apresentou melhor as características de ensino interdisciplinar, assumindo objetos de conhecimento de outras disciplinas, além da Química, sendo esta interdisciplinaridade uma das propriedades do enfoque CTS.

Sobre esta característica interdisciplinar Pinheiro, Silveira e Bazzo (2007, p. 81) apontam que os professores possuem pouco conhecimento em relação à abordagem CTS, 
evidenciando a necessidade de uma formação específica neste campo, isto é, a necessidade de temas CTS serem incluídos na formação inicial e continuada dos professores, para que estes possam contribuir para melhorar e inovar o ensino de Ciências, visando conseguir uma alfabetização científica e tecnológica mais ajustada às suas necessidades. A formação disciplinar é um problema que não está em harmonia com o comprometimento interdisciplinar do enfoque CTS, pois "nem nossos docentes, nem nossos alunos foram ou estão sendo formados dentro da perspectiva da interdisciplinaridade". Apesar da relevância comprovada da educação CTS, Maestrelli e Lorenzetti (2017) apontam a precariedade na formação inicial e continuada de professores e a ausência de propostas pedagógicas para justificar o desconhecimento de muitos professores sobre esta perspectiva educacional.

Essa escassa familiaridade dos professores com a abordagem CTS é evidente, apesar de que nos PCN já se registra referência ao currículo Ciência, Tecnologia e Sociedade (CTS), na seção relacionada às Ciências Naturais no Ensino Fundamental, assim como na Base Nacional Comum Curricular (BNCC) tanto do Ensino Fundamental quanto do Ensino Médio (BRASIL, 2018).

Como consequência deste contexto, os reflexos são evidentes na formação dos discentes. Em um estudo sobre exame nacional de desempenho de estudantes de Química, Santana, Wartha e Sampaio (2018, p. 46), inferem que

os estudantes concluintes de instituições públicas demonstram certa deficiência no que se refere ao desempenho quando se tratam de questões que demandam capacidades do pensamento crítico relacionadas a analisar argumentos apresentados, fazer e avaliar deduções por meio da interpretação de enunciados e atribuir juízo de valor a uma determinada informação, considerando os fatos relevantes e a consequência para determinadas ações.

Esse tipo de deficiência nos faz admitir que o tratamento dado a questões sociocientíficas e demais elementos da abordagem CTS, em questões do Enem, podem estimular o trabalho docente no ensino médio voltado para as relações da ciência com a tecnologia e a sociedade, o que teria o potencial de melhor qualificar a educação, tanto no nível básico quanto no superior.

\section{Considerações finais}

A análise da associação entre as questões de Química com os elementos do enfoque CTS, revelou que são raros os itens que abordam contextos concretos e em dinâmicas sociais, políticas e culturais dos aprendizes. Desse modo, não são exigidas reflexões de situações problemas da realidade dos estudantes. Nestes poucos itens se observa a exigência de habilidades e competências associadas a formação cidadã, característica inerente do enfoque CTS.

Desse modo, ficou demonstrado que um número menor de questões analisadas apresenta forte aproximação com o enfoque CTS, implicando a necessidade de uma reflexão crítica por parte dos estudantes, na abordagem de conhecimentos científicos como meio para as discussões das consequências para o meio ambiente e para a sociedade.

Observa-se com frequência que as questões associadas ao ensino de Química classificadas como "tradicionais", apesar de apresentarem possibilidade para discussões de 
problemas sociais importantes para a sociedade tem este potencial ignorado no processo de elaboração de itens, pois exigem dos respondentes apenas os conhecimentos escolares disciplinares, relevando a subjetividade implícita nas competências e habilidades requeridas com efetivo potencial CTS.

Neste estudo, observou-se que a frágil utilização dos objetos de conhecimento e das competências e habilidades para a formação de uma educação cidadã, ocorre, principalmente, pelo modo como a disciplina Química vem sendo tratada, com fim nela mesmo e não como meio, privilegiando a apreensão de conceitos, classificações e nomenclaturas, de modo excessivamente memorialístico, em detrimento de discussão de problemas sociais que podem ser contemplados neste campo de conhecimento.

Foi identificado um grupo considerável de itens "contextualizados", mas que apenas utilizam elementos do enfoque CTS como um processo de exemplificação, uma vez que não solicitam dos estudantes apreciações e julgamentos de problemas sociais e nem envolvem conhecimentos de outras áreas, caracterizando, assim, uma análise interdisciplinar, propriedade deste enfoque.

A baixa associação CTS, refletida na elaboração das questões de Química aplicadas no novo Enem, compromete os princípios que baseiam o exame, uma vez que, geralmente, ocorre o uso excessivo de conhecimentos com foco em conteúdos disciplinares de pouco significado para os alunos e que requerem, muitas vezes, somente a fixação de informações.

Esta pesquisa revela, portanto, que as questões do novo Enem apresentam aproximação, em diferentes níveis, com o enfoque Ciência, Tecnologia e Sociedade, mesmo tendo os objetos de conhecimento, as competências e as habilidades apresentado grande aproximação com as características do enfoque CTS.

Na Educação Básica, encontramos, com muita frequência, alunos refratários às aulas de Química. Assim, é necessária uma integração interdisciplinar dos conhecimentos, em decorrência da estreita relação entre os problemas escolares de Química e os problemas reais a serem resolvidos, que vão desde situações essenciais para a sociedade, como alimentação, até problemas ambientais. A partir desta perspectiva, os conhecimentos podem ser ensinados valorizando os conteúdos científicos, porém dentro de um contexto real, em uma proposta de participação na sociedade e mais interessante para o estudante.

\section{Referências}

AULER, Décio. Alfabetização científico-tecnológica: um novo paradigma? Ensaio - Pesquisa em Educação em Ciências, Belo Horizonte, v. 5, n. 1, p. 1-6, mar. 2003.

AULER, Décio. Enfoque Ciência-Tecnologia-Sociedade: pressupostos para o contexto brasileiro. Ciência \& Ensino, Campinas (SP), v. 1, número especial, nov. 2007.

AULER, Décio; BAZZO, Walter Antonio. Reflexões para a implementação do movimento CTS no contexto educacional brasileiro. Ciência \& Educação, Bauru (SP), v.7, n.1, p.1-13, 2001.

BAZZO, Walter Antonio. et al. (Ed.). Introdução aos Estudos CTS (Ciência, Tecnologia e Sociedade). Madrid. Organização dos Estados Ibero-americanos para a Educação, a Ciência e a Cultura (OEI), 2003. 172p. 
BRASIL. Ministério da Educação (MEC), Secretaria de Educação Básica. Orientações curriculares para o Ensino Médio - Ciências da Natureza, Matemática e suas Tecnologias, v. 2. Brasília, 2006. 135 p.

BRASIL. Ministério da Educação (MEC), Secretaria de Educação Média e Tecnológica (Semtec). PCN+ Ensino Médio: orientações educacionais complementares aos Parâmetros Curriculares Nacionais - Ciências da Natureza, Matemática e suas Tecnologias. Brasília: MEC/Semtec, 2002. 144p.

BRASIL. Ministério da Educação (MEC). Secretaria de Educação Básica. Diretrizes Curriculares Nacionais para a Educação Básica, Brasília, DF, 2013. 542 p. Disponível em http://basenacionalcomum.mec.gov.br. Acesso em: 16 abr. 2019.

BRASIL. Ministério da Educação. Secretaria de Educação Básica. Base Nacional Comum Curricular (BNCC), Brasília, DF, 2018. 600 p.

BRITO, Licurgo Peixoto de; GOMES, Nilzilene Ferreira. O Ensino de Física através de temas no atual cenário de ensino de Ciências. In: ENCONTRO NACIONAL DE PESQUISADORES EM EDUCAÇÃO EM CIÊNCIAS (ENPEC), 6., 2007, Florianópolis (SC). Anais...: Florianópolis (SC): ABRAPEC, 2007. p. 1-11.

COSTA-BEBER, Laís Basso; MALDANER, Otavio Aloisio. Um Estudo sobre as Características das Provas do Novo Enem: Um olhar para as questões que envolvem conhecimentos químicos. Química Nova na Escola, São Paulo, v. 37, n. 1, p. 44-52, fev. 2015.

FERNANDES, Carolina dos Santos; MARQUES, Carlos Aberto. Ciência, tecnologia e sociedade e a perspectiva freireana de educação: possíveis convergências. In: ENCONTRO NACIONAL DE PESQUISADORES EM EDUCAÇÃO EM CIÊNCIAS (ENPEC), 7., 2009, Florianópolis (SC). Anais...: Florianópolis (SC): ABRAPEC, 2009. p. 1-12.

FIRME, Ruth do Nascimento. A abordagem ciência-tecnologia-sociedade (CTS) no ensino da termoquímica: análise da construção discursiva de uma professora sobre conceitos científicos. 2012. 290 F. Tese (Doutorado) - Programa de Pós-Graduação em Educação, Centro de Educação, Universidade Federal de Pernambuco, Recife, 2012.

GIL, Antonio Carlos. Didática do Ensino Superior. São Paulo: Atlas, 2010. 286 p.

LÓPEZ CEREZO, José Antonio. Ciencia, Tecnología y Sociedad: el estado de la cuestión en Europa y Estados Unidos. Revista Iberoamericana de Educación, n. 18, p. 41-68, 1998.

LUDKE, Menga; ANDRÉ, Marli E. D. A. Pesquisa em educação: abordagens qualitativas. São Paulo: EPU, 1986.

MAESTRELLI, Sandra Godoi; LORENZETTI, Leonir. As relações CTSA nos anos iniciais do Ensino Fundamental: analisando a produção acadêmica e os livros didáticos. Amazônia: Revista de Educação em Ciências e Matemática. Belém, v.13 (26), p. 05-21, jan-jun, 2017.

MASCIO, Carlos César. Exame Nacional do Ensino Médio (Enem): articulações entre a educação Ciência, Tecnologia e Sociedade e a proposta nacional para o ensino de química. 2009, 100 f. Dissertação (Mestrado) - Universidade Federal de São Carlos, São Carlos (SP), 2010.

MORAES, Roque. Uma tempestade de luz: a compreensão possibilitada pela análise textual discursiva. Ciência \& Educação, Bauru (SP), v.9, n. 2, p.191-211, 2003. 
MORAES, Roque; GALIAZZI, Maria do Carmo. Análise textual discursiva: processo reconstrutivo de múltiplas faces. Ciência \& Educação, Bauru (SP), v.12, n.1, p.117-128, 2006

MORAES, Roque; GALIAZZI, Maria do Carmo. Análise Textual Discursiva. ljuí: Editora Unijuí, 2007. 224 p.

PINHEIRO, Nilcéia Aparecida Maciel; SILVEIRA, Rosemari Monteiro Castilho Foggiato; BAZZO, Walter Antonio. Ciência, Tecnologia e Sociedade: a relevância do enfoque CTS para o contexto do Ensino Médio. Ciência \& Educação, Bauru (SP), v.13, n. 1, p.71-84, 2007.

PINHEIRO, Nilcéia Aparecida Maciel; SILVEIRA, Rosemari Monteiro Castilho Foggiatto; BAZZO, Walter Antonio. O contexto científico-tecnológico e social acerca de uma abordagem crítico-reflexiva: perspectiva e enfoque. Revista Iberoamericana de Educación. EDITA: Organización de Estados Iberoamericanos para la Educación, la Ciencia y la Cultura (OEI). n. 49/1, marzo, 2009.

PRUDÊNCIO, Christina Andréa Vianna. Perspectiva CTS em estágios curriculares em espaços de divulgação científica: contributos para a formação inicial de professores de Ciências e Biologia. 2013. 149 f. Tese (Doutorado em Educação) - Programa de Pós-Graduação em Educação, Centro de Educação e Ciências Humanas, Universidade Federal de São Carlos, São Carlos (SP), 2014.

REIS, Pedro; GALVÃO, Cecilia. Os professores de Ciências Naturais e a discussão de controvérsias sociocientíficas: dois casos distintos. Revista Electrónica de Enseñanza de las Ciencias, Espanha, v.7, n.3, p.746-772, 2008.

SANTANA, Edenilza Mendonça de; WARTHA, Edson José; SAMPAIO, Murilo de Medeiros. O exame nacional de desempenho dos estudantes de Química: análise comparativa entre iniciantes e concluintes. Amazônia - Revista de Educação em Ciências e Matemáticas, Belém, v.14 (32), p. 33-47, jul-dez, 2018.

SANTOS, Wildson Luiz Pereira dos et al. Química e sociedade: um projeto brasileiro para o ensino de química por meio de temas CTS. Educació Química (EduQ), n. 3, p. 20-28, 2009.

SANTOS, Wildson Luiz Pereira dos. Contextualização no ensino de ciências por meio de temas CTS em uma Perspectiva crítica. Ciência \& Ensino, Campinas (SP), v.1, número especial, nov, 2007.

SANTOS, Wildson Luiz Pereira dos; MORTIMER, Eduardo Fleury. Uma análise de pressupostos teóricos da abordagem C-T-S (Ciência-Tecnologia-Sociedade) no contexto da educação brasileira. Ensaio - Pesquisa em Educação em Ciências, Belo Horizonte, v. 2, n. 2, p. 1-12, 2002.

SANTOS, Wildson Luiz Pereira dos; SCHNETZLER, Roseli Pacheco. Educação em Química: Compromisso com a cidadania. 4. ed. rev. atual. ljuí (RS): Unijuí, 2010. 159 p.

SANTOS, Wildson Luiz. Pereira dos. Aspectos sócio-científicos em aulas de química. 2002. 336 f. Tese (Doutorado em Educação), Faculdade de Educação, Universidade Federal de Minas Gerais, Belo Horizonte, 2002.

SILVA, Camila Silveira da; OLIVEIRA, Luiz Antonio Andrade de. Formação inicial de professores de química: formação específica e pedagógica. In: NARDI, Roberto (Org). Ensino 
de ciências e matemática I: temas sobre a formação de professores. São Paulo: Editora UNESP; São Paulo: Cultura Acadêmica, 2009. cap. 3, p. 43-57.

SOUZA, Jorge Raimundo da Trindade; BRITO, Licurgo Peixoto de. Influência do conteúdo de Química na elaboração de questões do novo Enem associadas ao enfoque CTS. Revista Brasileira de Pesquisa em Educação em Ciências, Belo Horizonte, v. 18, n. 21, p. 699-726, ago. 2018.

SOUZA, Jorge Raimundo da Trindade; VALENTE, José Alexandre da Silva; ALMEIDA, Ana Cristina Pimentel Carneiro de; BRITO, Licurgo Peixoto de. Ilhas interdisciplinares de racionalidade no ensino de ciências: uma experiência didática no PARFOR na Ilha do Marajó, Pará, Brasil. Amazônia: Revista de Educação em Ciências e Matemática, Belém, v.12 (24), p.85-98, jan-jul, 2016. 